\title{
Manual strangulation of the uterine isthmus after placental removal to reduce blood loss during cesarean section
}

Isil Uzun Cilingir, Ayse Karahasanoglu, Aysegul Deregozu, Mucize Ozdemir, Fehmi Yazicioglu

Süleymaniye Maternity and Education and Research Hospital, Istanbul, Turkey

Submitted: 20 February 2018; Accepted: 18 June 2018

Online publication: 3 December 2019

Arch Med Sci 2021; 17 (4): 915-919

DOI: https://doi.org/10.5114/aoms.2019.90334

Copyright (@) 2019 Termedia \& Banach

\section{Abstract}

Introduction: This study aimed to evaluate the effect of manual strangulation of the uterine isthmus on the amount of blood loss during cesarean section. Material and methods: This is a prospective randomized controlled trial. A total of 118 participants were enrolled in the study. Manual strangulation of the uterine isthmus just after placental removal was performed during cesarean section in group I ( $n=57$; the strangulation group). Strangulation was not performed in group II ( $n=61$; the control group). Preoperative and postoperative venous blood hemoglobin, capillary hemoglobin, and absorbed blood levels during the operation were compared between the two groups. Results: The median age of the patients was 28.5 (19-41). The median body mass index of the patients in the study was 27 (21-42). There were no significant differences in the demographic characteristics of the patients between the groups. The median difference between the preoperative and postoperative 4-6 h capillary hemoglobin values was significantly lower in the strangulation group (2.0 (0-9)) than in the control group (3.0 (0-8)). The amount of absorbed blood during the operation was also significantly lower in the strangulation group $(164.5 \mathrm{ml}(69-1310))$ than in the control group (230 $\mathrm{ml}(35-3223)$ ).

Conclusions: Manual uterine strangulation of the uterine isthmus immediately after the removal of the placenta may induce a 30\% decrease in blood loss during cesarean section.

Key words: manual strangulation, cesarean section, postpartum bleeding, delivery.

\section{Introduction}

Cesarean delivery is the most common major surgery with increased risks of maternal morbidity and mortality compared with women who deliver vaginally $[1,2]$. It also has specific complications not seen in vaginal delivery $[3,4]$.

Cesarean sections are also characterized by high blood loss compared with vaginal delivery $[5,6]$. An increase in the rate of postpartum hemorrhage has been attributed to the rise of cesarean deliveries [7, 8]. Increased blood loss during delivery causes numerous complications and elevated morbidity [9]. Based on a study from the early 1960s, blood loss $<1000 \mathrm{ml}$ was accepted as normal during cesarean delivery [10]. In developing countries with high incidence of anemia, the reduction in

\author{
Corresponding author: \\ Dr. Işı Uzun Çilingir \\ Süleymaniye Maternity \\ and Education and Research \\ Hospital \\ Yedikule Konakları B4/D4 \\ Istanbul, Turkey \\ Phone: +90 5325141526 \\ E-mail: isiluzu@gmail.com
}


blood loss during cesarean section may have significant benefits for women's health.

Reduction in intraoperative blood loss is beneficial for patients by decreasing postoperative morbidity and need for blood transfusions. A decrease in the amount of blood loss will also reduce anemia, fatigue, and weakness in the postpartum period. This may have a positive effect on postpartum healing, psychological state and breastfeeding. So the techniques which decrease the blood loss during delivery may have an important role for a healthy postpartum period.

In this study, we investigated the effect of manual uterine strangulation after removal of the placenta on the amount of blood loss during cesarean section.

\section{Material and methods}

A total of 118 patients with term pregnancy who underwent uneventful cesarean section between December 2010 and January 2013 were included in this prospective randomized study. The patients with high risk for postpartum hemorrhage (macrosomia >4500 g, severe polyhydramnios, placenta previa, history of atony) any medical or pregnancyrelated disease, morbid obesity, or multiple pregnancies were excluded from the study.

The study was approved by a local ethics committee. The patients were randomly assigned to the strangulation group (group I) and the control group (group II). A computer program was used to randomly assign the patients (random number generator, Segobit software, Issaquah, WA, USA). Manual strangulation of the uterine isthmus was performed during cesarean section in group I ( $n=57$; the strangulation group), whereas strangulation was not performed in group II $(n=61$; the control group).

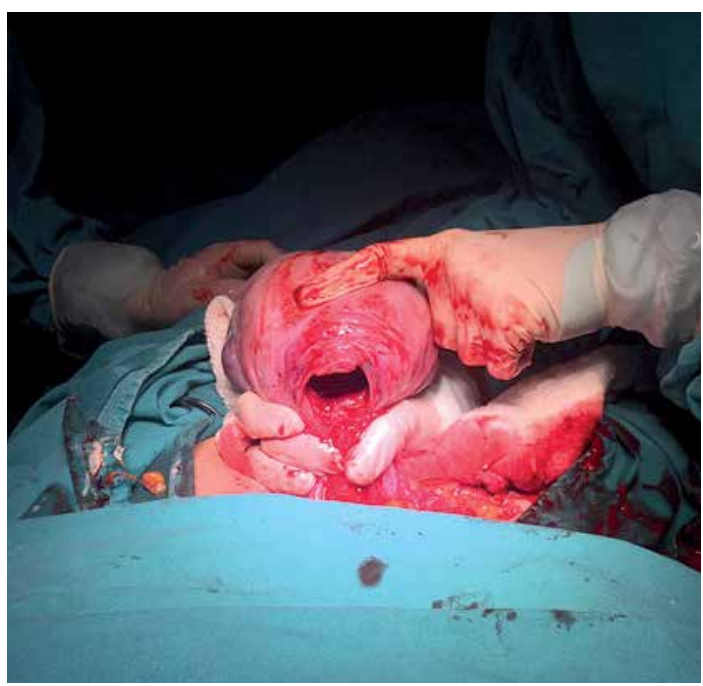

Figure 1. Manual strangulation of the uterus after placental removal
All cesarean sections were performed by two experienced surgeons in obstetric surgery under general anesthesia. Immediately after the removal of the placenta, the uterus was taken to the extraabdominal area. Subsequently, manual strangulation of the uterine isthmus was performed. The uterine isthmus was strangulated by the left hand of the operator from the posterior site of the uterine isthmus for $3 \mathrm{~min}$ (Figure 1). Cesarean section was then completed. The uterine wall was sutured by one layer of continuous locking No. 1 polyglactin suture (Ethicon Inc. Somerville, NJ, USA).

To accurately determine the amount of blood loss during the operation, the weights of the sponges and towels were measured by sensitive digital scales before and after the operation by the blinded author. The difference between the wet and dry sponges was accepted as the amount of absorbed blood.

A complete blood count of the peripheral venous blood was measured by an automatic blood counter (Abbot Cell-Dyn 3700, Abbot Diagnostics, IL, USA) before the operation and 4-6 h after the operation. Simultaneously, capillary hematocrit values of patients were measured immediately before the operation and 4-6 $\mathrm{h}$ after the operation.

All patients received prophylactic antibiotic (1 g of cefazolin/IV) immediately before the operation. Postpartum care was identical in the groups. Intravenous infusion of oxytocin (20 U) was started intraoperatively after the removal of the placenta and continued in the early postoperative period.

The following parameters were compared between the two groups: mean maternal age, gestational weeks at delivery, birth weight, body mass index, presentation and situs of the fetus, cesarean indications, cervical examination at delivery, uterine contractions before delivery, placental localization, rupture of membranes before delivery, absorbed blood by sponges during the operation, operation time, preoperative and postoperative hemoglobin and hematocrit values, preoperative and postoperative capillary hemoglobin values, postoperative changes in hemoglobin, hematocrit, white blood cells, thrombocytes, C-reactive protein, and capillary hemoglobin values, hospital stay, and postpartum lactation.

The sample size was calculated by the Gpower (v3.1.7) program. The power of the work is expressed as 1- $\beta$ ( $\beta=$ probability of type $\|$ error) and in general, research should have at least $80 \%$ power. According to Cohen's effect size coefficients, it was decided that there should be at least 26 people in the groups according to the calculation made assuming that the evaluations to be made between the two independent groups would have a large effect size $(d=0.80)$. 


\section{Statistical analysis}

Statistical analysis was performed with Number Cruncher Statistical System (NCSS) 2007 (Kaysville, UT, USA). Data were analyzed using descriptive statistical procedures (mean, median, frequency, standard deviation, minimum, and maximum). Student's $t$-test was used to compare normally distributed variables, whereas the Mann-Whitney $U$ test was conducted to compare variables that were not normally distributed. Statistical significance was set at $p<0.01$ and $p<0.05$.

\section{Results}

Demographic characteristics were similar between the groups (Table I). No statistically significant differences in the mean gestational age at delivery and preoperative hemoglobin, hematocrit, white blood cell, thrombocyte, and C-reactive protein values were found between the two groups. Cesarean indications, cervical examination at delivery, number of uterine contractions, and birth weight were also similar between the two groups $(p>0.05)$. In addition, no significant difference was determined in the operation time and hospital stay between the groups $(p>0.05)$.

No significant differences were observed between the groups in postoperative changes in hemoglobin, hematocrit, thrombocyte, white blood cell, and C-reactive protein values in the total blood count at 4-6 $\mathrm{h}$ after the operation. Meanwhile, statistically significant differences were noted in postoperative changes in capillary hemoglobin values and in the amount of absorbed blood between the groups (Table II).

The difference between the preoperative and postoperative 4-6 h capillary hemoglobin values was significantly lower in the strangulation group
(2.0 (0-9) than in the control group (3.0 (0-8); $p=0.014)$. The amount of absorbed blood during the operation was also significantly lower in the strangulation group (164.5 $\mathrm{ml}(69-1310))$ than in the control group (230 $\mathrm{ml}(35-3223) ; p=0.005)$ (Table II, Figures 2 and 3).

\section{Discussion}

In our study, we measured the actual quantity of the blood loss by weighing the absorbed blood loss during cesarean section and early postpartum hemoglobin changes, which may reflect the blood loss better. The difference between the preoperative and postoperative capillary hemoglobin values and absorbed blood during the operation was significantly lower in the strangulation group than in the control group. Additionally, this technique did not extend the operation time significantly.

In the United States, 50 million maternal records were analyzed between 1998 and 2009 to identify severe obstetric morbidities during delivery. For every maternal death, approximately 200 women experience severe morbidity. Transfusions were found to be the most common cause of maternal morbidity during delivery [11]. Postpartum hemorrhage remains the major cause of maternal mortality [12].

Evidently, the reduction in bleeding during delivery has clinical significance. Oxytocin is the most commonly used agent for the prevention of hemorrhage during cesarean delivery. It also has many advantages [13]. A recently published meta-analysis showed that misoprostol as an adjunct to oxytocin is more effective than oxytocin alone for reducing intraoperative and postoperative blood loss during cesarean delivery [8]. So studies for alternative drugs, combinations and techniques in the prevention of obstetric hemor-

Table I. Demographic characteristics of the groups

\begin{tabular}{|c|c|c|c|}
\hline \multirow[t]{2}{*}{ Parameter } & \multicolumn{2}{|c|}{ Manual strangulation } & \multirow[t]{2}{*}{$P$-value } \\
\hline & No $(n=61)$ & Yes $(n=57)$ & \\
\hline \multicolumn{4}{|l|}{ Age: } \\
\hline Min-max (median) & $20-41(27)$ & $19-40(29)$ & \multirow[t]{2}{*}{$0.859^{A}$} \\
\hline Mean \pm SD & $28.70 \pm 4.74$ & $28.86 \pm 4.66$ & \\
\hline \multicolumn{4}{|c|}{ Body mass index $\left[\mathrm{kg} / \mathrm{m}^{2}\right]$ : } \\
\hline Min-max (median) & $21-39(27)$ & $21-42(28)$ & \multirow[t]{2}{*}{$0.176^{A}$} \\
\hline Mean \pm SD & $27.93 \pm 4.06$ & $29.05 \pm 4.86$ & \\
\hline \multicolumn{4}{|l|}{ Operation time [min]: } \\
\hline Min-max (median) & $20-90(32)$ & $18-55(30)$ & \multirow[t]{2}{*}{$0.304^{\mathrm{A}}$} \\
\hline Mean \pm SD & $33.13 \pm 10.20$ & $31.39 \pm 7.87$ & \\
\hline
\end{tabular}


Table II. Results of manual strangulation

\begin{tabular}{|c|c|c|c|}
\hline \multirow[t]{2}{*}{ Variable } & \multicolumn{2}{|c|}{ Manual strangulation } & \multirow[t]{2}{*}{$P$-value } \\
\hline & No $(n=61)$ & Yes $(n=57)$ & \\
\hline \multicolumn{4}{|c|}{ Absorbed blood volume [ml]: } \\
\hline Min-max (median) & $35-3223(230)$ & $69-1310(164.5)$ & ${ }^{b} 0.005^{* *}$ \\
\hline Mean \pm SD & $288.37 \pm 399.55$ & $201.47 \pm 168.63$ & \\
\hline \multicolumn{4}{|l|}{ Delta capillary Hct (\%): } \\
\hline Min-max (median) & $0-8(3)$ & $0-9(2)$ & b0.014* \\
\hline Mean \pm SD & $2.95 \pm 1.89$ & $2.19 \pm 1.68$ & \\
\hline \multicolumn{4}{|l|}{ Delta Hct (\%): } \\
\hline Min-max (median) & $0-6(1.9)$ & $0-7(1.4)$ & bo.242 \\
\hline Mean \pm SD & $1.97 \pm 1.35$ & $1.78 \pm 1.51$ & \\
\hline \multicolumn{4}{|l|}{ Delta HB [gr/dl]: } \\
\hline Min-max (median) & $0-7(0.7)$ & $20-2.2(0.5)$ & ${ }^{\mathrm{b}} 0.149$ \\
\hline Mean \pm SD & $0.78 \pm 0.91$ & $0.59 \pm 0.47$ & \\
\hline \multicolumn{4}{|l|}{ Delta WBC [/mm³]: } \\
\hline Min-max (median) & $100-12,800(4000)$ & $400-12,300(4000)$ & b0.981 \\
\hline Mean \pm SD & $4240.26 \pm 2880.08$ & $4229.93 \pm 2687.46$ & \\
\hline \multicolumn{4}{|l|}{ Delta PLT [/ml]: } \\
\hline Min-max (median) & $8000-93,000(19,000)$ & $1000-67,000(18,000)$ & ${ }^{\mathrm{b}} 0.336$ \\
\hline Mean \pm SD & $26,660.16 \pm 20,936.86$ & $21,528.07 \pm 14,555.99$ & \\
\hline \multicolumn{4}{|l|}{ Delta CRP [mg/l]: } \\
\hline Min-max (median) & $0-33.4(3.2)$ & 0-91 (2.4) & b0.597 \\
\hline Mean \pm SD & $5.48 \pm 8.10$ & $4.63 \pm 11.98$ & \\
\hline
\end{tabular}

${ }^{b}$ Mann-Whitney U test, ${ }^{* *} p<0.01,{ }^{*} p<0.05$. Delta: Preoperative value - postoperative value. Hct - hematocrit, HB - hemoglobin, $W B C$ - white blood cells, PLT - platelets, CRP - C-reactive protein.

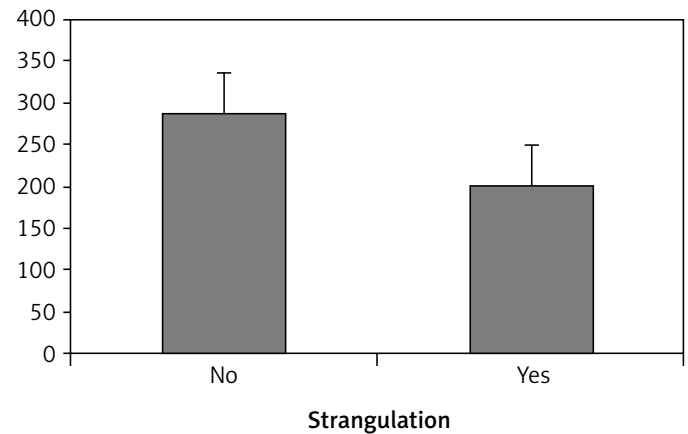

Figure 2. Amount of absorbed blood loss

rhage are needed to develop more effective and economic strategies.

In our study, simple manual strangulation of the uterus after removal of the placenta was useful for reducing bleeding during the operation. The

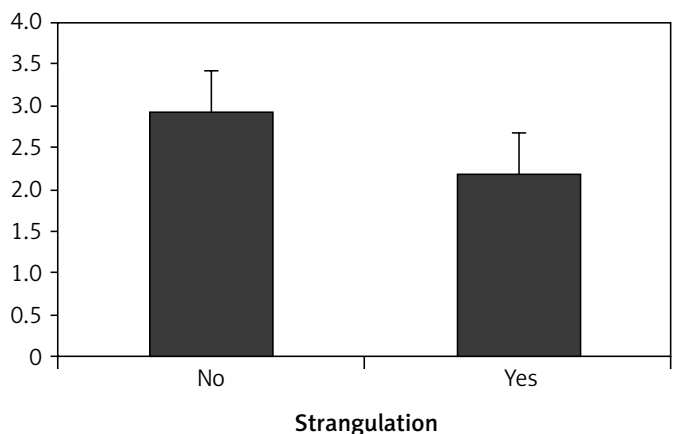

Figure 3. Delta capillary hematocrit (difference between preoperative and postoperative hematocrit)

technique is easy to perform and does not require extensive experience or any special equipment. Routine manual strangulation of the uterus may be offered in elective cesarean section to reduce blood loss during the operation. Ikeda et al. recommended 
provisory manual compression of both parametria followed by rubber tourniquet as a lifesaving procedure in cases of placenta accreta [14]. Recently Yazıcıoğlu et al. reported that manual strangulation of the uterus may reduce bleeding during cesarean section. They concluded that the mean difference between preoperative and postoperative $24 \mathrm{~h}$ haematocrit values was significantly lower in the manual strangulation group [15].

Significantly lower levels of blood absorbed by sponges and towels showed that the remaining blood collection will decrease if this technique is performed. This approach may reduce the need for Douglas aspiration during the operation and decrease postoperative adhesions and the incidence of febrile morbidity in the early postoperative period.

Postpartum anemia has been reported in $25 \%$ of women who suffered from puerperal morbidity at eight weeks after delivery. The most common puerperal morbidity was fatigue (59\%) [16]. These kinds of puerperal morbidities may also decrease via routine manual strangulation of the uterus.

Manual strangulation of the uterus may also be performed for the prevention of postpartum hemorrhage. It may lead to a decrease in the dosage of uterotonic agents. Further studies are needed to determine the difference in the amount of uterotonic agents.

In particular, patients who have risks for uterine atony (such as macrosomia, multiparity, and multiple gestations) are good candidates for manual strangulation. In the case of postpartum hemorrhage, prompt detection and quick management are essential. The amount of blood loss before detection is critical. In certain cases, blood loss can be underestimated and hemodynamic shock rapidly arises. Manual strangulation can be useful for gaining time by reducing blood loss.

In our study, the hemoglobin values of capillary blood and venous blood were measured at 4-6 h after the operation. We showed that capillary hemoglobin values and absorbed blood volume were changed by manual uterine strangulation. The decrease in bleeding did not reflect the venous blood parameters. Similarly, the measurements might be implemented at $24 \mathrm{~h}$ after surgery to yield the best results.

In conclusion, simple manual uterine strangulation after removal of the placenta is an effective technique for decreasing bleeding during cesarean section. This technique might be helpful in reducing postpartum anemia, need for blood transfusions, mortality, and morbidity after cesarean sections.

\section{Conflict of interest}

The authors declare no conflict of interest.

\section{References}

1. Hall MJ, DeFrances CJ, Williams SN, Golosinskiy A, Schwartzman A. National Hospital Discharge Survey: 2007 summary. Nat Health Stat Report 2010; 29: 24.

2. Boyle A, Reddy UM. Epidemiology of cesarean delivery: the scope of the problem. Semin Perinatol 2012; 36: 308-14.

3. Clarck SL, Koonings PP, Phelan JP. Plasenta accreata and prior cesarean section. Obstet Gynecol 1985; 66: 89-92.

4. Ciebiera M, Ciebiera M, Czekańska-Rawska M, Jakiel G. Laparoscopic isthmocele treatment - single center experience. Videosurgery and Other Miniinvasive Techniques 2017; 12: 88-95.

5. Ahmed B, Abu Nahia F, Abushama M. Routine cervical dilatation during elective cesarean section and its influence on maternal morbidity: a randomised controlled study. J Perinat Med 2005; 33: 510-3.

6. Meikle S, Steiner CA, Zhang J, Lawrance WL. A national estimate of the elective primary cesarean delivery rate. Obstet Gynecol 2005; 105: 751-6.

7. Begley CM, Gyte GM, Murphy DJ, Devane D, Mc Donald SJ, Mc Guire W. Active versus expectant managament for women in the third stage of labour. Cochrane Database Syst Rev 2010; 7: CD007412.

8. Conde-Agudelo A, Nieto A, Rosas-Bermudez A, Romero R. Misoprostol to reduce intraoperative and postoperative hemorrhage during cesarean delivery: a systematic review and metaanalysis. Am J Obstet Gynecol 2013; 209: 40.e1-40.e17.

9. Creanga A, Bateman B, Butwick A, et al. Morbidity associated with cesarean delivery in the United States: is placenta accreta an increasingly important contributor? Am J Obstet Gynecol 2015; 213: 384.

10. Pritchard JA, Baldwin RM, Dickey JC, Wiggins KM, Reed GP, Bruce DM. Blood volume changes in pregnancy and the puerperium, II: red blood cell loss and changes in apparent blood volume during and following vaginal delivery, cesarean section, and cesarean plus total hysterectomy. Am J Obstet Gynecol 1962; 84: 1271-82.

11. Callaghan WM, Creange AA, Kuklina EV. Severe maternal morbidity among delivery and postpartum hospitalizations in the United states. Obstet Gynecol 2012; 120: 1029.

12. Berg CJ, Callaghan WM, Syverson C, Henderson Z. Pregnancy related mortaliy in the Uniteds States, 1998 to 2005. Obstet Gynecol 2010; 116: 1302-5.

13. Abdelazim I, Farghali M, Elbiaa A, et al. Impact of antenatal oxytocin infusion on neonatal respiratory morbidity associated with elective cesarean section. Arch Med Sci 2017; 13: 629-34.

14. Ikeda T, Sameshima H, Kawaguchi H, Yamauchi N, Ikenoue T. Tourniquet technique prevents profuse blood loss in placenta accreta cesarean section. Obstet Gynaecol Res 2005; 31: 27-31.

15. Yazicioglu HF, Çapar S, Sevket O, Keskin S, Ateş S. Use of manual strangulation technique to reduce blood loss at elective cesarean section. Pam Med J 2014; 7: 27-31.

16. Glazener CM, Abdalla M, Stroud P, Naji S, Templeton A, Russell T. Postnatal maternal morbidity: extent, causes, prevention and treatment. Br J Obstet Gynecol 1995; 102: 282-5. 